\title{
Study on Prevention and Control of Heavy Metal Pollution Risk in Industrial Parks
}

\author{
Chengjun Wang ${ }^{1}$, Yong Liu ${ }^{2}$, Dongyuan Wang ${ }^{3}$ \\ ${ }^{1}$ School of Management, Xi'an Univ. of Arch. \& Tech., Xi'an 710055, China \\ ${ }^{2}$ School of Science, Xi'an Univ. of Arch. \& Tech., Xi'an 710055, China \\ ${ }^{3}$ School of Information \& Control Engineering, Xi'an Univ. of Arch. \& Tech., Xi'an 710055, \\ China
}

\section{工业园区土壤重金属污染风险防控预警研究}

\author{
王成军 ${ }^{1}$, 刘 勇 $^{2}$, 王冬源 ${ }^{3}$ \\ '西安建筑科技大学管理学院, 西安 710055, 中国 \\ ${ }^{2}$ 西安建筑科技大学理学院, 西安 710055 , 中国 \\ ${ }^{3}$ 西安建筑科技大学信息与控制工程学院, 西安 710055 , 中国
}

\begin{abstract}
At present, the prevention and control of heavy metal pollution in soil has become a hot issue in environmental management. Industrial Parks are the harder-hit areas of heavy metal pollution in soil. Early warning of heavy metal pollution in soil is an effective way to prevent the risk of heavy metal pollution in industrial parks. This paper studies the prevention and control and early warning of soil heavy metals from two aspects: pollution area and pollution risk level of heavy metal. Two early-warning indicators for early warning of area and risk level of heavy metal pollution in soil are put forward in industrial parks. Through the research on the prevention and control of heavy metal pollution risk in soil in typical industrial parks, it will provide reference for the prevention and control of heavy metal pollution in industrial parks.
\end{abstract}

Keywords: industrial park; soil; heavy metal pollution; warning

\section{摘要}

目前土壤重金属污染的防控已经成为 环境管理的热点问题, 工业园区作为土壤重
金属污染的重灾区, 土壤重金属污染预警是 对于工业园区土壤重金属污染风险防范的 有效手段。本文从工业园区土壤重金属污染 范围和污染风险程度两个方面研究土壤重 金属防控预警问题，提出工业园区土壤重金 属污染范围预警与污染风险程度预警两个 预警指标。通过对典型工业园区土壤重金属 污染风险防控预警研究, 为工业园区土壤重 金属污染风险防控提供借鉴。

关键词: 工业园区; 土壤；重金属污染；预 警

据环境保护部与国土资源部 2014 年 4 月 17 日公布的《全国土壤污染状况调查公 报》, 涉及重金属的企业或工业园区已经成 为重金属污染的一个主要源头, 周边土壤污 染问题及环境危害事件也越来越多的被报 道。长期以来, 频繁爆发的污染事故损失惨 重, 不仅增加了环境保护治理成本, 也使社 会稳定成本大增, 而土壤污染修复所需的费 用更是天价。2 015 年 11 月《国家环境保护 “十三五” 科技发展规划》进一步明确提出 了要进一步继续环境风险防控技术开发。强 化风险防范和预警, 从源头上进行主动管理, 促进我国环境向风险管理战略转变。土壤重 金属污染预警是对于工业园区土壤重金属 
污染风险防范的有效手段, 我国尚未针对工 业园区土壤重金属污染开展实质性的风险 预警管理研究。本文主要针对工业园区土壤 重金属污染防控研究土壤重金属污染范围 预警和土壤重金属状态预警。

\section{1. 土壤重金属污染预警指标}

土壤重金属污染预警指标针对工业园 区预警区域进行评价。工业园区土壤重金属 污染预警指标的选取要兼顾到影响范围和 污染状态, 能够从多个角度反映土壤潜在危 害的程度。工业园区土壤重金属污染预警指 标应能够准确反映土壤重金属污染的主要 特征, 有准确的数据来源, 规范的土壤环境 安全标准, 合理的数据处理方法。针对土壤 重金属污染范围及污染状态及其引发的土 壤重金属污染状态, 从土壤重金属污染范围、 土壤重金属污染状态两方面, 考虑土壤重金 属污染特征、重金属潜在危害的程度、应急 响应与处置四个特征主题, 并根据土壤重金 属污染危险程度的影响要素, 依据工业园区 土壤重金属污染影响范围与状态选取 2 个预 警指标。

\section{1 工业园区土壤重金属污染范围}

工业园区是土壤重金属污染的重点区 域, 对工业园区及周边土壤重金属污染范围 进行及时预警是土壤环境质量管理的必要 条件。对土壤重金属污染限值的选取是判定、 预测土壤重金属污染范围的关键。从当前发 展形势看, 《土壤环境质量标准》( GB 15618-1995) 远不能适应环境保护要求, 2015 年 1 月 13 日环境保护部决定修订《土 壤环境质量标准》(GB 15618-1995)。我国
铅土壤环境背景水平偏低, 适度收严土壤中 的铅含量限值, 有利于及时反映土壤铅含量 上升、累积的趋势 [1]。对于工业园区及周 边, 土壤重金属含量一般超过了当地土壤背 景值, 因此在土壤重金属污染调查中采用高 于当地背景值的《土壤环境质量标准》(GB 15618-1995）一级标准来确定工业园区土壤 重金属污染范围。

\section{2 工业园区土壤重金属污染风险状态}

土壤重金属污染评价是对土壤重金属 污染状况的定量描述和评定, 即按照一定的 评价标准和评价方法对一定区域范围内的 土壤环境质量进行说明、评定和预测, 其目 的是准确反映土壤重金属污染状况, 为有针 对性地采取措施提供科学依据。目前土壤环 境评价方法很多, 研究目的是选取评价方法 的重要依据。本研究是为了清楚描述工业园 区及周边土壤重金属的污染状况, 因此对工 业园区及周边土壤利用 “潜在生态危害指数 法” 进行土壤重金属污染评价。“潜在生态 危害指数法” 是国际上土壤重金属研究的方 法之一, 它结合环境化学、生物毒理学、生 态学等方面的内容, 以定量的方法划分出重 金属潜在危害的程度 [2-4]。目前, 将 Hakanson 潜在生态危害指数用于评价土壤 重金属污染状况时, 各国学者所选择的参比 值差别较大, 本文以当地土壤重金属背景值 为参比值, 该参比值能更确切反映土壤的实 际污染程度。重金属生态危害程度的划分依 据 Hakanson 提出的分级标准 [5]。

表 1 重金属污染潜在生态危害指标与分级关系

\begin{tabular}{cccc}
\hline 潜在生态风险参 & 单因子污染物生态风险程度 & 潜在生态风险指数 $R I$ & $\begin{array}{c}\text { 总的潜在生态风 } \\
\text { 数 } E_{r}^{i}\end{array}$ \\
\hline$E_{r}^{i}<40$ & 轻度 & $R I<150$ & 低度 \\
$40 \leq E_{r}^{i}<80$ & 中等 & $150 \leq R I<300$ & 中度 \\
$80 \leq E_{r}^{i}<160$ & 强 & $300 \leq R I<600$ & 重度 \\
$160 \leq E_{r}^{i}<320$ & 很强 & & 严重 \\
$E_{r}^{i} \geq 320$ & 极强 & $R I \geq 600$ & \\
\hline
\end{tabular}


计算公式如下 ${ }^{[5]}$ :

$$
\begin{aligned}
& C_{f}^{i}=C_{i} / S_{i} \\
& E_{r}^{i}=T_{r}^{i} \times C_{f}^{i} \\
& R I=\sum_{i=1}^{n} E_{r}^{i}
\end{aligned}
$$

式中, $C_{f}^{i}$ 为某重金属的污染参数; $C_{i}$ 为土壤

中重金属的实测含量; $S_{i}$ 为计算所需的参比值;

$E_{r}^{i}$ 为潜在生态风险系数; $T_{r}^{i}$ 为单个污染物的 毒性相应参数 $(\mathrm{Pb} 、 \mathrm{Zn} 、 \mathrm{Cu} 、 \mathrm{Cr} 、 \mathrm{As} 、 \mathrm{Cd}$ 和 $\mathrm{Hg}$ 的毒性响应参数分别为 $5 、 1 、 5 、 2 、 10$ 、 30 和 40$) ; R I$ 为多种金属潜在生态风险指数。

\section{2. 工业园区土壤重金属污染预警模型}

\section{1 土壤重金属污染范围预警模型构建}

污染范围预警的目标是判定重金属污 染影响范围, 准确判定重点防控区域土壤重 金属污染范围直接关系到是否有必要采取 环境管理措施。为了有的放矢的对研究区的 土壤重金属污染进行预警和管理, 以采样监 控数据为数据源, 根据土壤重金属浓度超出 本底值最高限制建立模型, 预警模型如下:

利用有限采样点在研究区域对各个重金 属浓度进行内插值, 得到区域内的各个点重金 属浓度预测值, 定义污染为有一种重金属超出 背景值则为土壤污染。

$$
\alpha(x, y)=\left\{\begin{array}{l}
0, k_{i}(x, y) \leq k_{0 i} \\
1, k_{i}(x, y)>k_{0 i}
\end{array}\right.
$$

其中, $k_{0 i}$ 为当地土壤重金属第 $i$ 种土壤重金属 背景值, $k_{i}(x, y)$ 为经纬度确定位置的预测的 第 $i$ 种土壤重金属浓度值, $\alpha(x, y)$ 为经纬度 确定位置的土壤重金属是否污染的判定函数。

\section{2 土壤重金属污染风险状态预警模型构 建}

在研究区域上划分 $1000 \mathrm{~m} * 1000 \mathrm{~m}$ 的网格, 研究网格内的采样点重金属浓度数据, 根据土 壤重金属浓度超出本底值范围建立模型, 预警 模型如下:

$$
\beta(n)=\left\{\begin{array}{cc}
\text { 低度 } & \mathrm{RI}<150 \\
\text { 中度 } & 150 \leq \mathrm{RI}<300 \\
\text { 重度 } & 300 \leq \mathrm{RI}<600 \\
\text { 严重 } & \mathrm{RI} \geq 600
\end{array}\right.
$$

$\mathrm{RI}$ 为网格划分区域内土壤重金属污染潜 在生态风险指数, $\beta(n)$ 为第 $n$ 个网格划分区 域的总的潜在生态风险程度判定函数。

\section{3. 实证研究}

\section{1 研究区域概况}

研究区域位于陕西西部某工业园区, 园区 面积 48 平方公里, 其中建设规划面积 11 平方 公里, 工业规划面积 5 平方公里。工业园区主 要的涉铅企业主要有三家, 分别为铅锌冶炼厂、 焦化厂和热电厂。该区域三面环山, 地势西北 高东南低, 呈簛箕形由西北向东南倾斜, 河谷 海拔最低 $595 \mathrm{~m}$, 土壤以垆土类为主, 土层深 厚, 通透性和蓄水性能良好 ${ }^{[6]}$ 。

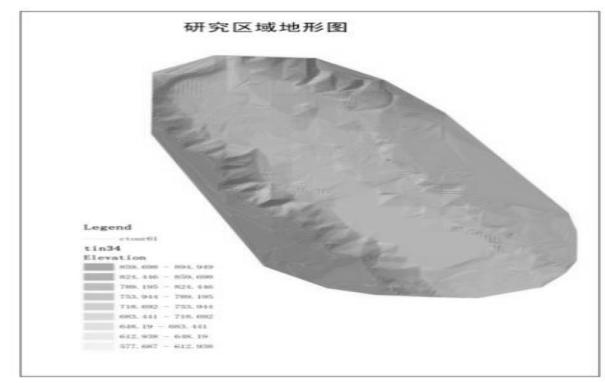

图 1 研究区域地形 


\section{2 工业园区及周边土壤重金属污染预警}

\subsection{1 土壤重金属污染范围预警}

工业园区及周边土壤是受到重金属污染 风险的重点区域, 如果用当地土壤重金属背景 值比较, 所有采样点均已有污染, 因此本文用 《土壤环境质量标准》(GB15618-1995) 一级标 准高于当地背景值作为污染阀值计算土壤重
金属污染预警范围。在工业园区范围内, 依据 工业园区厂区分布及地形设计采用方案。采集 土壤样检测土壤中 $\mathrm{Pb} 、 \mathrm{Zn} 、 \mathrm{Cu} 、 \mathrm{Cr} 、 \mathrm{As} 、 \mathrm{Cd}$ 和 $\mathrm{Hg}$ 的重金属含量。为了研究清楚工业园区 及周边土壤重金属污染状态, 本文把研究区域 网分, 对不同的地块分别进行独立的采用潜在 生态危害指数法评价。

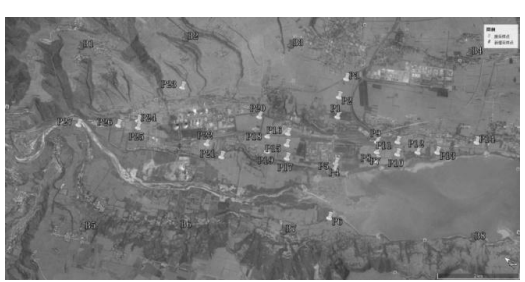

图 2 土壤采样点分布图

表 2 土壤中重金属的描述性统计分析结果 ${ }^{[5]}$

\begin{tabular}{|c|c|c|c|c|c|c|c|c|c|}
\hline 元素 & $\begin{array}{l}\text { 最大值 } \\
/(\mathrm{mg} \cdot \mathrm{kg}-1)\end{array}$ & $\begin{array}{l}\text { 最小值 } \\
/(\mathrm{mg} ・ \mathrm{~kg}-1)\end{array}$ & $\begin{array}{l}\text { 平均值 } \\
/(\mathrm{mg} \cdot \mathrm{kg}-1)\end{array}$ & $\begin{array}{l}\text { 标准差 } \\
/(\mathrm{mg} \cdot \mathrm{kg}-1)\end{array}$ & $\begin{array}{l}\text { 变 异 } \\
\text { 系数 }\end{array}$ & 偏度 & 峰度 & $\begin{array}{l}\text { 土壤重金属 } \\
\text { 一级标准 } \\
/(\mathrm{mg} ・ \mathrm{~kg}-1)\end{array}$ & $\begin{array}{l}\text { 当地土 } \\
\text { 壤元素 } \\
\text { 背景值 } \\
/(\mathrm{mg} \cdot \mathrm{kg}-1)\end{array}$ \\
\hline $\mathrm{Pb}$ & 124 & 20.9 & 49.55 & 26.33 & 0.53 & 1.34 & 0.96 & 35.0 & 25.4 \\
\hline $\mathrm{Zn}$ & 203 & 66.3 & 112.26 & 39.73 & 0.35 & 1.02 & -0.25 & 100 & 69.2 \\
\hline $\mathrm{Cu}$ & 38.5 & 25.5 & 30.37 & 3.08 & 0.10 & 1.09 & 1.26 & 35 & 24.7 \\
\hline $\mathrm{Cr}$ & 585 & 67.6 & 117.16 & 112.66 & 0.96 & 3.65 & 12.93 & 90 & 68.2 \\
\hline As & 20.9 & 11.5 & 15.51 & 1.98 & 0.13 & 0.4 & 1.19 & 15 & 15.0 \\
\hline $\mathrm{Cd}$ & 2.45 & 0.11 & 0.84 & 0.63 & 0.75 & 1.04 & 0.06 & 0.20 & 0.19 \\
\hline $\mathrm{Hg}$ & 1.30 & 0.02 & 0.21 & 0.23 & 1.10 & -0.33 & 0.34 & 0.15 & 0.058 \\
\hline
\end{tabular}

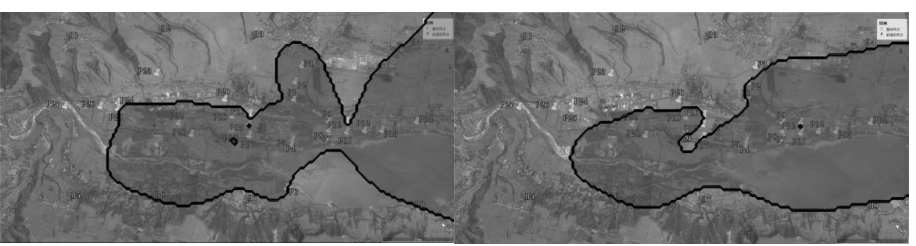

图 3 重金属 $\mathrm{Pb}$ 和 $\mathrm{Zn}$ 工业园区土壤污染影响范围

\subsection{2 土壤重金属污染风险状态预警}

为了研究清楚工业园区及周边土壤重金 属污染风险状态, 本文把研究区域网分, 对不 同的地块分别进行独立的采用潜在生态危害 指数法评价。利用 Hakanson 潜在生态危害指 数法及其划分标准, 得到工业园区划分不同地
块的土壤重金属污染风险。

对研究区域划分地块土壤中重金属潜在 生态风险计算结果用 MATLAB 结合判定函数软 件进行可视化处理, 图 4 中颜色越重或越鲜艳 的地块土壤重金属污染风险越高, 直观预警工 业园区不同地块的土壤重金属污染风险程度。 
表 3 研究区域划分地块土壤中重金属潜在生态风险计算结果

\begin{tabular}{|c|c|c|c|c|c|c|c|c|c|c|c|}
\hline $\begin{array}{l}\text { 地 块 } \\
\text { 编号 }\end{array}$ & $\begin{array}{c}R I \\
\text { 值 }\end{array}$ & $\begin{array}{l}\text { 污 染 } \\
\text { 等级 }\end{array}$ & $\begin{array}{l}\text { 地 块 } \\
\text { 编号 }\end{array}$ & $\begin{array}{c}R I \\
\text { 值 }\end{array}$ & $\begin{array}{l}\text { 污 染 } \\
\text { 等级 }\end{array}$ & $\begin{array}{l}\text { 地 块 } \\
\text { 编号 }\end{array}$ & $R I$ 值 & $\begin{array}{l}\text { 污 染 } \\
\text { 等级 }\end{array}$ & $\begin{array}{l}\text { 地 块 } \\
\text { 编号 }\end{array}$ & $\begin{array}{l}R I \\
\text { 值 }\end{array}$ & $\begin{array}{l}\text { 污 染 } \\
\text { 等级 }\end{array}$ \\
\hline 1 & 131.01 & 低度 & 14 & 277.82 & 中度 & 27 & 503.35 & 重度 & 40 & 405.01 & 重度 \\
\hline 2 & 58.54 & 低度 & 15 & 83.28 & 低度 & 28 & 369.18 & 重度 & 41 & 117.95 & 低度 \\
\hline 3 & 136.81 & 低度 & 16 & 56.37 & 低度 & 29 & 516.22 & 重度 & 42 & 83.37 & 低度 \\
\hline 4 & 112.78 & 低度 & 17 & 240.38 & 中度 & 30 & 629.54 & 严重 & 43 & 83.91 & 低度 \\
\hline 5 & 73.63 & 低度 & 18 & 232.01 & 中度 & 31 & 56.62 & 低度 & 44 & 48.52 & 低度 \\
\hline 6 & 155.61 & 中度 & 19 & 333.84 & 重度 & 32 & 103.37 & 低度 & 45 & 104.49 & 低度 \\
\hline 7 & 208.71 & 中度 & 20 & 462.91 & 重度 & 33 & 208.62 & 中度 & 46 & 66.43 & 低度 \\
\hline 8 & 180.56 & 中度 & 21 & 70.18 & 低度 & 34 & 297.07 & 中度 & 47 & 117.18 & 低度 \\
\hline 9 & 174.30 & 中度 & 22 & 126.92 & 低度 & 35 & 246.89 & 中度 & 48 & 221.30 & 中度 \\
\hline 10 & 235.75 & 中度 & 23 & 258.63 & 中度 & 36 & 216.51 & 中度 & 49 & 124.75 & 低度 \\
\hline 11 & 73.31 & 低度 & 24 & 833.35 & 严重 & 37 & 279.33 & 中度 & 50 & 220.19 & 中度 \\
\hline 12 & 161.26 & 中度 & 25 & 356.60 & 重度 & 38 & 456.55 & 重度 & & & \\
\hline 13 & 291.73 & 中度 & 26 & 278.37 & 中度 & 39 & 373.60 & 重度 & & & \\
\hline
\end{tabular}

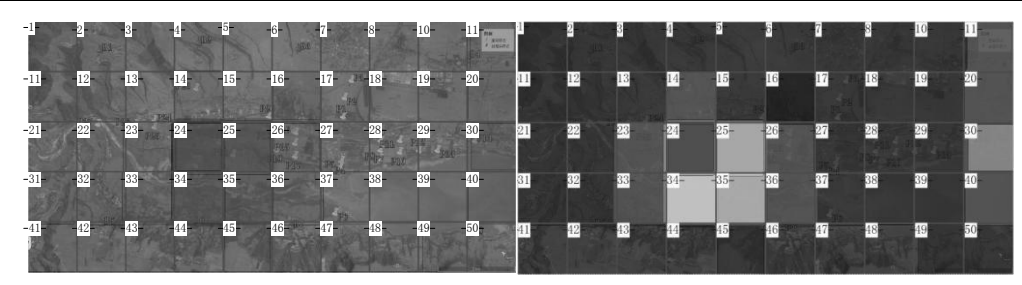

图 4 研究区域土壤重金属污染风险状况网格划分

\section{4. 结论}

（1）利用插值的方法进行土壤重金属范 围预警, 在土壤采样点有限的情况下, 可以方 便、较为准确的识别出重金属含量超过背景值 并且需要重点防控的区域, 能为政府提供该地 域是否需要采取环境管理措施的依据。

(2) “潜在生态危害指数法” 可以科学的 划分研究区域土壤重金属污染的程度, 对一定 区域范围内的土壤环境质量进行说明、评定和 预测。还可以得到选定地块土壤重金属的生态 风险和对土壤的污染程度, 使政府可以有针对 性的制定防控、治理土壤重金属污染措施。

\section{致谢}

本研究得到了陕西省社科项目 “基于企业污染 行为选择的陕西省工业园区土壤重金属污染 防控管理体系研究” (项目编号: 2017S001) 和陕西省自然科学基础研究计划项目 “工业园 区土壤重金属污染防控体系研究” (项目编码: 2018JM7003）资助。

\section{参考文献}

[1] 《土壤环境质量标准》修订项目组, 《农 用地土壤环境质量标准 (征求意见稿)》 和《建设用地土壤污染风险篮选指导值 (征求意见稿)》编制说明 $[\mathrm{EB} / \mathrm{OL}]$, http://www.mep.gov.cn/gkml/hbb/bgth/201 501/W020150115340486559262.pdf , 2014-12/2018-1-7

[2] 周建军,周桔,冯仁国. 我国土壤重金属污 染现状及治理战略. 中国科学院院刊, 2014, 29(03):315-320+350+272.

[3] 范拴喜, 甘卓亭, 李美娟, 张掌权,周旗. 土 壤重金属污染评价方法进展，中国农学 通报,2010,26(17):310-315.

[4] 赵沁娜, 徐启新, 杨凯. 潜在生态危害指数 法在典型污染行业土壤污染评价中的应 用. 华东师范大学学报 (自然科学 版),2005(01):111-116.

[5] 刘勇, 王成军, 冯涛, 等. 重金属在铅锌冶 炼厂内的空间分布及污染评价. 西北大 
学学报 (自然科学版), 2014, 44(1): 133-140.

[6] 刘勇,王成军,刘华,冯涛,马红周,张琼华,孙 大林. 铅同位素解析技术在工业园污染
溯源中的应用. 环境工程学报, 2015, 9(06): 3031-3036. 